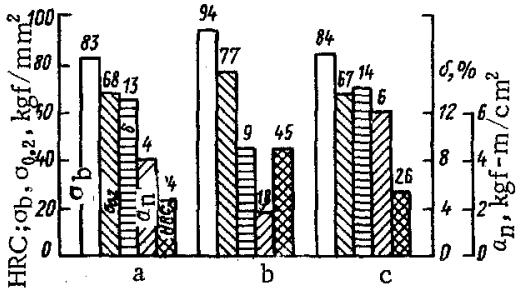

Fig. 2

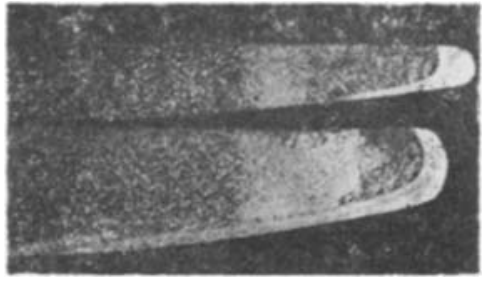

Fig. 3

Fig. 2. Mechanical properties of steel $15 \mathrm{Kh} 11 \mathrm{MF}$ specified (a), after facing with steel $20 \mathrm{Kh} 13$ (b), and after tempering at $660^{\circ}$ (c).

Fig. 3. Macrostructure of two sections of the vane after facing, tempering, and induction hardening. $2 \times$.

It should be noted that tempering after facing facilitates final machining of vanes (to restore the dimensions and shape) due to the $100 \%$ drop in the hardness of the facing and the heat-affected zone.

Also, if the vane warps in the process of facing, then tempering permits it to be straightened with almost any degree of deformation.

The advantage of these tempering conditions is that the vane is heated at temperatures not exceeding the tempering temperature of blanks for turbine vanes of steel $15 \mathrm{Kh} 11 \mathrm{MF}$, which guarantees constant mechanical properties after retempering.

It is known that steel with a single-phase martensitic structure has the highest resistance to cavitationerosion failure [3]. To create a wear-resistant layer after tempering and mechanical finishing, the leading edges of the vanes are induction hardened.* Figure 3 shows the macrostructure of the cross section after this treatment. Analysis of the results of erosion resistance tests showed that the erosion resistance of vanes faced with steels containing $12 \% \mathrm{Cr}$, then tempered and induction hardened, is $50-100 \%$ higher than after electrospark hardening with alloy T15K6 and 3-5 times higher than after quenching + tempering.

\title{
CONCLUSIONS
}

1. To obtain the necessary operating characteristics after facing of worn vanes from steam turbines, the heat treatment should consist of high-temperature tempering and induction hardening.

2. The best mechanical properties, meeting the requirements, are obtained by facing steel $15 \mathrm{Kh} 11 \mathrm{MF}$ with steel $20 \mathrm{Kh} 13$ and tempering at $660^{\circ}$.

\section{LIT ERATURE CITED}

1. I. I. Frumin et al., "Restoration of worn vanes from steam turbines, " Energ. Elektrif., No. 3, 18 (1974).

2. N. A. Pogrebnoi et al., "Repair of vanes from steam turbines after erosion wear," Tekhnol. Organ. Proizvod., No. 11, 55 (1976).

3. I. N. Bogachev, Cavitation Failure and Cavitation-Resistant Alloys [in Russian], Metallurgiya, Moscow (1972), pp. 51, 74 .

\section{ERRATA}

In issue No. 2 (1979) the Theory section should include the name of L. V. Podobedov after V. N. Yarmosh and p. 114 should read L. V. Podobedov instead of L. V. Podobedova.

\footnotetext{
* Inventor's Certificate No. 373315.
} 